\title{
Robust short-term memory in the neuronal field model involving nonlinear dendritic integration Hiroki Kurashige* and Hideyuki Câteau
}

\author{
Address: RIKEN BSI-TOYOTA Collaboration Center, RIKEN, Wako, Saitama 351-0198, Japan \\ Email: Hiroki Kurashige* - kura@brain.riken.jp \\ * Corresponding author
}

from Eighteenth Annual Computational Neuroscience Meeting: CNS*2009

Berlin, Germany. 18-23 July 2009

Published: 13 July 2009

BMC Neuroscience 2009, I0(SuppI I):P288 doi:I0.II86/I47I-2202-I0-SI-P288

This abstract is available from: http://www.biomedcentral.com//47/-2202//0/SI/P288

(C) 2009 Kurashige and Câteau; licensee BioMed Central Ltd.

Several studies has suggested that a single dendritic branch can be a computational subunit which locally integrate the synaptic inputs to produce dendritic action potential (dAP) [1]. In the present study, we investigate the influence of dAPs on the network dynamics by using a neuronal two-field model incorporating the dendrite nonlinearly. We discuss functional significance of the unique dynamics present in our model.

Our network model consists of two fields (Figure 1): (1) somatic field representing a squarely arrayed soma of neurons whose dynamics are described by the Izhikevich model [2], (2) dendritic field representing a squarely arrayed dendritic branches whose long-lasting $\mathrm{Ca}^{2+}$ action potentials are described by the Morris-Lecar model. The dynamical variables actually sit on lattice points placed in the two fields. Each soma on the somatic field innervates to a disk-shaped area in the dendritic field according to the observed axonic arborization and a disk-shaped area on the dedritic field in turn delivers dendritic currents to each soma on the dendritic field according to the observed dendritic arborization. Actual innervation to the dendritic field from a given soma and current injection from the dentric field to the soma are determined probabilistically according to Gaussian distributions with different widths. The soma-to-dendrite signaling happens only when the somatic action potential (sAP) occurs. The dendrite-tosoma signaling happens continually. A particularly strong signal is sent from the dendritic field when dAP occurs. We test long and short durations of $\mathrm{dAP}$ since a wide ranges (up to a few hundreds of msec) of dAP duration have been reported [3].

First, we studied the network dynamics of the model in response to constant external currents with short-lasting or long-lasting dAP. In both cases, we observed the spatially clustered patterns of sAPs, which were gradually deformed. The deformation was slower in case of the long-lasting dAP than in the case of the short-lasting dAP. However, the difference did not simply reflect the difference in the time constants of the two dynamics. Next, we applied the external strong noise to somatic field. As expected, noise destroyed patterns rapidly in the case of the short-lasting dAP. Surprisingly however, in the case of long-lasting $\mathrm{dAP}$, the pattern was more robustly preserved than in the noiseless case. We expect that this robustness has advantage for information storage, thus may lead to novel mechanism for short-term memory. Figure 2.

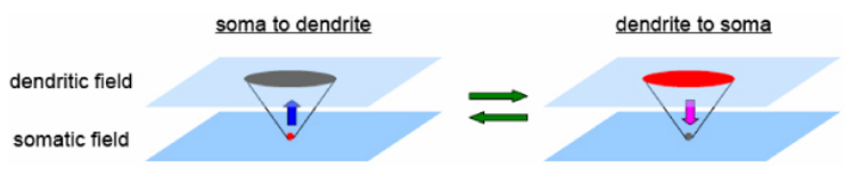

Figure I

Two-field model. The blue and magenta arrow expresses the synaptic inputs to and the dendritic currents from the subpopulation of dendritic field, respectively. 

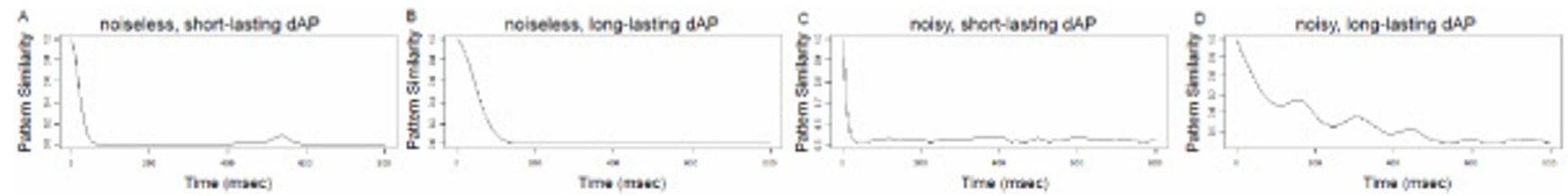

Figure 2

Measuring the persistence of spatial patterns based on the similarity between the patterns at different points in time.

\section{References}

I. Polsky A, Mel BW, Schiller J: Computational subunits in thin dendrites of pyramidal cells. Nat Neurosci 2004, 7:62 I-627.

2. Izhikevich EM: Simple model of spiking neurons. IEEE Trans Neural Netw 2003, I4:1569-1572.

3. Wei DS, Mei YA, Bagal A, Kao JP, Thompson SM, Tang CM: Compartmentalized and binary behavior of terminal dendrites in hippocampal pyramidal neurons. Science 200I, 293:2272-2275.

Publish with Biomed Central and every scientist can read your work free of charge

"BioMed Central will be the most significant development for disseminating the results of biomedical research in our lifetime. "

Sir Paul Nurse, Cancer Research UK

Your research papers will be:

- available free of charge to the entire biomedical community

- peer reviewed and published immediately upon acceptance

- cited in PubMed and archived on PubMed Central

- yours - you keep the copyright

Submit your manuscript here:

http://www.biomedcentral.com/info/publishing_adv.asp 